\title{
Speech as a stimulus for differential vocal behavior in the mynah bird (Gracula religiosa)
}

\author{
Joseph H. Grosslight, Wesley C. Zaynor and Barry L. Lively
}

KENT STATE UNIVERSITY

\begin{abstract}
Abstraet
Discrimination of auditory inputs and consequent vocal control in the mynah bird is an important preliminary to speech acquisition. The highly specialized sound isolation chambers may restrict the development of a vocal discriminated operant. In two related studies, a discriminated vocal operant was produced by reinforcing vocal behavior in the presence of specific auditory input (Hello, Hello) and non-reinforcing others (I talk and/or silence).
\end{abstract}

The interest in the mynah bird as a research organism has centered, in our laboratory, around his speech acquisition ability. Prior to direct experimental concern with speech acquisition, a number of questions primarily related to this bird's vocal behavior has to be investigated. The first of these questions bore directly upon the operant nature of vocal responses. The work of Grosslight (1962), Lane (1961), and Ginsburg (1960) have satisfied reasonably well the concern for vocal operant responses.

A second major question related to vocal behavior and eventually to speech acquisition by the mynah is the bird's ability to discriminate different speech sounds (as inputs) and then to vary his vocal behavior accordingly. The latter question is not a new one in the psychological literature since the discriminated operant is well established. For research investigating differential procedures, particularly of reinforcement, as they relate to speech acquisition in the mynah, the control of vocal behavior by different auditory input stimuli takes on added significance.

This additional significance of the discriminated vocal operant for research in speech acquisition in the mynah bears upon two considerations that have arisen from our current research experience with these birds. First, it is necessary to demonstrate an auditory discriminated operant as part of the specification of necessary and sufficient conditions to produce talking birds. Second, the nature of our highly controlled and restricted environmental conditions (Grosslight, Harrison and Weiser, 1962; Grosslight and Lively, 1963) produce extreme sound isolation and deprivation which may have an inhibitory effect upon eventual speech acquisition in these birds. From our observations to date, this effect could manifest itself as non-attending to the speech input stimulus and consequent nondiscrimination of auditory cues. The following studies provided positive evidence in relation to the mynah's ability to discriminate auditory input and to control vocal behavior accordingly.

Six mynahs of uncertain age, but under a year, were trained to emit a vocal response of at least . $3 \mathrm{sec}$. in duration in order to activate a feeder and thereby gain access to food (reinforcement). This procedure and the effect of reinforcement on vocal rate has been reported elsewhere (Grosslight, Harpison and Weiser, 1962). Following this establishment of a high vocal rate, speech training was attempted by playing the words "Hello, Hello" (via programmed tape recording) once every $45 \mathrm{sec}$. for six 30-min. periods a day. This procedure was continued for eighteen days. Monitoring of the vocal behavior of the birds indicated no shift from the usual vocal pattern toward the auditory input of "Hello, Hello." Most important of all, the birds did not appear to be attending or responding in any noticeable fashion to this auditory stimulus.

In order to determine whether or not the birds could respond to the speech input, the following two studies were performed. In both studies, the birds were required to differentially control their vocal responses as a function of the audi-

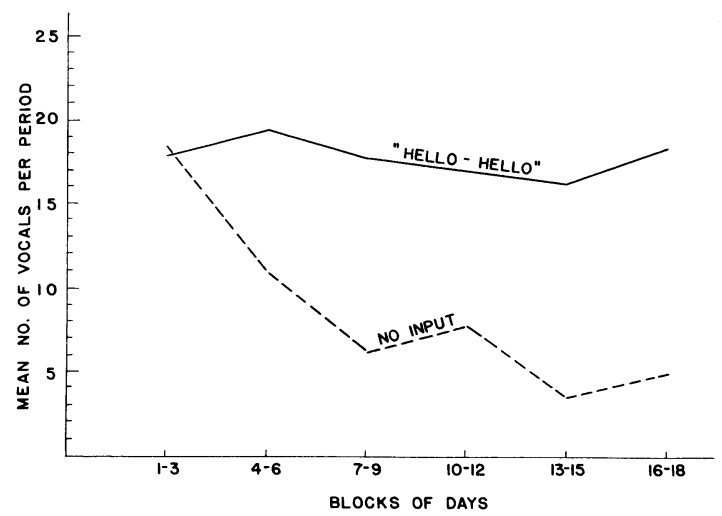

Fig. 1. Mean number of criterion vocals under input of "Hello-Hello" (reinforced) and NO-input (nonreinforced) in blocks of five days for eighteen days of discrimination training. 
tory-input condition. In this discriminated vocal operant research, the following question can be investigated: Can there be established a significant difference in vocal rate between two speech input conditions?

In the first study, vocal responses were reinforced only during the play in of the phrase "Hello, Hello." The stimulus control words of "Hello, Hello" were presented once every 45 sec., in six 30-min. periods, distributed throughout a nine-hour light cycle day. Criterion vocalizations during any of the silence periods $(6 \mathrm{hrs}$. total) did not lead to reinforcement. This differential reinforcement procedure was maintained for eighteen days. All birds learned this discrimination (Fig. 1) so that vocal responses were emitted primarily during speech input periods, and relative silence was maintained by the birds during non-play-in (silence) periods. The difference between the median number of vocalizations in play-in and non-play-in periods is significant beyond the .001 level (non-parametric sign test).

A possible source of contamination in stimulus input discrimination exists in the above study. There is a strong possibility that some consistent but irrelevant cue, such as the initial pop of the tape recorder or other electronic noise, was the true discriminated stimulus input. In order to eliminate this possible contamination and to extend the stimulus control problem, the birds were now required to discriminate among three auditory stimulus input conditions: (1) "Hello, Hello," (2) "I talk," and (3) silence or non-speech but with the tape recorder and incidental electronic stimulus elements present. Only during the "Hello, Hello" play-in period could the birds gain access to the feeder (reinforcement) following vocal responses. In each day, the reinforceable condition of "Hello, Hello" was presented once every $30 \mathrm{sec}$. in twelve $15-\mathrm{min}$. periods distributed throughout the nine-hour cycle. The non-reinforceable conditions of "I talk" and no-speech occurred with the same time characteristics and distribution. The birds learned this discrimination and related vocal control as attested by the mean number of vocals emitted under each condition for the six test

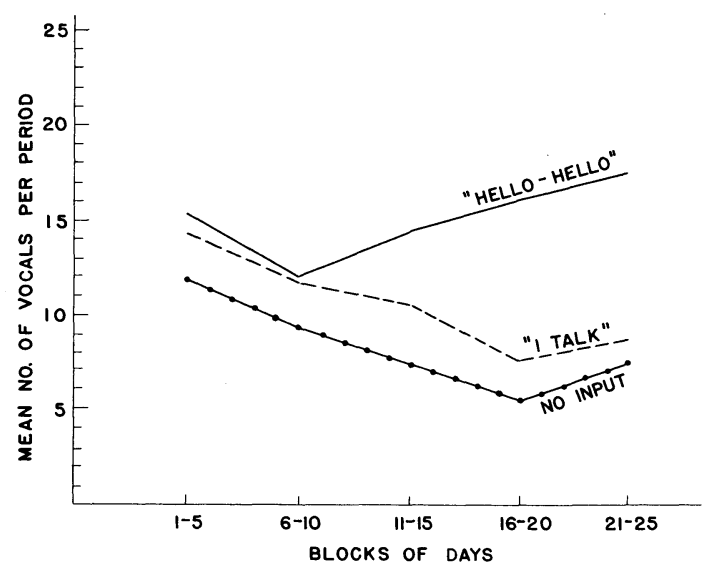

Fig. 2. Mean number of criterion vocals under input of "Hello-Hello" (reinforced), "I talk" (nonreinforced) and NO-input (with electronic noise) (nonreinforced) in blocks of five days for twenty-five days of discrimination training.

days (Fig. 2). An analysis of variance of these results indicates significance at the .01 level of confidence for the main effect. Therefore it is reasonable to conclude that the mynah can discriminate between speech inputs and control his vocal behavior accordingly.

\section{References}

GINSBURG, N. Conditioned vocalization in the Budgerigar. J. comp. physiol. Psychol., 1960, 53, 183-186. GROSSLIGHT, J. H., HARRISON, P. and WEISER, C. Reinforcement control of vocal responses in the mynah bird (Gracula religiosa). Psychol. Rec., 1962, 12, 193-201.

GROSSLIGHT, J. H. and LIVELY, B. L. The mynah bird (Gracula religiosa) as a laboratory organism: Some general observations. Psychol. Rec., 1963, 1, 1-9.

LANE, H. Operant control of vocalizing in the chicken. J. exp. Anal. Beh.,1961, 4, 171-177.

\section{Acknowledgments}

Portions of this study were presented at the meetings of the American Association for the Advancement of Science, December, 1962 in Philadelphia, Penna.

This research was supported by GrantGB-335 from the National Science Foundation. 